$$
\begin{array}{r}
\text { ENTRELAÇAN } \\
\text { MULHERES E PLAN } \\
\text { ENSAIO FOTOETNOGRÂF } \\
\text { DO MUNDO DA R } \\
\text { NO RIO NEQ }
\end{array}
$$




\section{ENTRELAÇANDO MULHERES E PLANTAS: \\ ENSAIO FOTOETNOGRÁFICO \\ DO MUNDO DA ROÇA \\ NO RIO NEGRO}

\section{TH I A G MOTA CARDOSO}


No Rio Negro as roças são lugares multiespécie, lócus do entrelaçamento entre humanos e múltiplas espécies de plantas, animais, insetos e entes protetores. Fruto da derrubada e queima da floresta e do manejo da paisagem, as roças acolhem uma miríade de vidas que agem para crescer e se desenvolver em seu processo espaço-temporal ressurgente ${ }^{1}$.

O presente trabalho fotoetnográfico busca adentrar neste mundo, expressando a relação profunda e de codesenvolvimento entre mulheres indígenas (Baré, Tukano, Piratapuia) e plantas na região do Rio Cuieiras, afluente do Rio Negro em seu baixo curso. São mulheres que migraram com seus parentes para localidades próximas a Manaus, um grande centro urbano amazônico e, mesmo diante das adversidades, vem cotidianamente recriando seus lugares vitais, tecendo suas malhas relacionais e transmitindo seus conhecimentos (Cardoso 2010).

No Rio Negro, saber-fazer-crescer e manter uma rica diversidade de plantas é mostrar uma grande virtuosidade agronômica e uma valorização pelo mundo multiespécie (Emperaire et al. 2012). Mulheres se entrelaçam com as plantas em suas roças, expressando uma percepção refinada sobre a vida das plantas, reconhecendo suas animacidades e agencialidades numa malha na qual estabelecem relações de reciprocidade e cuidado. É esta mesma forma de se engajar no mundo que não permite que se descartem organismos de qualquer forma e que se valoriza a incorporação de novas variedades e espécies de plantas cultivadas, como a mandioca. Ao infligirem uma perturbação na paisagem criando as roças, as agricultoras indígenas buscariam dar condições para o pleno desenvolvimento e crescimento de plantas, com a perpetuação de relações biossociais e não entre sujeito e objeto ou entre natureza e cultura, como pressupõe ontologias naturalistas.

Um exemplo destas relações pode ser visto entre as mulheres e destas com as mandiocas e as roças, em especial com a mãe da roça. Uma entidade ao mesmo tempo material-espiritual que determina relações, pensamentos e sentimentos na prática agrícola. É com a mãe da roça que a mulher deve manter conversações para que tenha plantas saudáveis em locais protegidos, tendo boas colheitas.

No entrelaçar com as plantas as mulheres lidam com a diferença de corpos, incorporando conhecimentos e práticas ecológicas e agronômicas de um leque de agrobiodiversidade (mais de setenta variedades de mandioca, por exemplo), enfatizando o quanto os saberes agronômicos locais incorporam a noção de diversidade e se contrapõem à "monocultura da mente" dos projetos modernista de desenvolvimento agrícola ${ }^{2}$. Produzir, considerando as exigências ecológicas de dezenas de espécies e variedades, a heterogeneidade dos ambientes relacionais, a coordenação entre diferentes ritmos de vida e o suprimento das demandas domésticas representam uma empresa de alta complexidade. Gerenciar relações neste sistema complexo é manejar os riscos inerentes às relações sempre incertas, ao assegurar uma durabilidade 
fundamentada em uma estreita articulação entre duas esferas de atuação, a do manejo das plantas e a do manejo temporal e espacial das roças, articuladas com suas casas de farinha, capoeiras, quintais e matas: o seja, cuidar de uma roça é gerenciar relações em processos ressurgentes.

Realizado entre 2004 e 2010, este ensaio fotoetnográfico segue o fluxo dos acontecimentos numa roça e fora dela. São eventos onde pessoas se encontram com plantas em ritmos de vida diferenciados, buscando acoplar seus tempos e tecer a textura de seus mundos. Assim de forma alguma pretendo com estas imagens representar os sistemas agrícolas rio negrino e as relações que lhes dão vida e movimento, pois, certamente, as fotografias que apresento neste ensaio são sínteses de histórias de vida e de plantas, um olhar fotoetnográfico (Achutti, 1997) da vida vivida e de momentos singulares.

As fotografias deste ensaio foram obtidas ao longo de uma série de projetos de pesquisa e ação em que estive envolvido no Rio Negro, no Amazonas. É, ao mesmo tempo, parte de minha dissertação de mestrado defendida no programa de pós-graduação em Ecologia do Instituto Nacional de Pesquisas da Amazônia (Inpa), publicada em livro (Cardoso, 2010) e de projetos como o "Etnobotânica e Manejo Agroflorestal", desenvolvido desde 2006 pelo Instituto de Pesquisas Ecológicas. A pesquisa também esteve vinculada ao projeto "Populações Locais, Agrobiodiversidade e Conhecimentos Tradicionais na Amazônia Brasileira" (Pacta), convênio entre Conselho Na- cional de Pesquisa Científica (CNPq), Universidade Estadual de Campinas (Unicamp) e o Institut de Recherche pour le Développement (IRD), sob coordenação do Dr. Mauro William Barbosa de Almeida, da Unicamp, e Dra. Laure Emperaire, do IRD. O objetivo do projeto foi o de identificar os processos biológicos e socioculturais que geram a agrobiodiversidade na Amazônia brasileira, e que são indissociáveis da produção e transmissão dos saberes associados às plantas cultivadas.

Busquei associar os dados etnográficos e ecológicos com a fotografia, numa proposta de captar os elementos da prática agrícola e apresentá-los sob o enfoque visual. Utilizei-me de uma simples câmera Pentax K1000 com uma lente de $50 \mathrm{~mm}$, analógica, robusta para um campo prolongado, onde inseri filmes em P\&B Kodak Tri-X ISO 400.

\section{NOTAS}

${ }^{1}$ Os sistemas agrícolas do Rio Negro foram patrimonializados como $\mathrm{Pa}$ trimônio Imaterial pelo Instituto do Patrimônio Histórico e Arquitetônico Nacional (IPHAN).

${ }^{2}$ Monocultura da mente, uma metáfora oriunda da prática agrícola e florestal da monocultura, que separa "cientificamente" os domínios florestais dos agrícolas e privilegia, na floresta, a retirada de madeira e na agricultura, o cultivo de um único produto tendo em vista objetivos capitalistas. Segundo Shiva (2003) a monocultura da mente, ao promover o desaparecimento da diver- 
sidade na nossa percepção, elimina-a do próprio mundo, é um modo de pensar que não responde adequadamente à diversidade.

\section{REFERÊNCIAS BIBLIOGRÁFICAS}

Achutti, L.E.R. 1997. Fotoetnografia: um estudo de antropologia visual sobre cotidiano, lixo e trabalho. Porto Alegre: Tomo Editorial/ Livraria Palmarinca.

Cardoso, T.M. 2010. Saber biodiverso: práticas e conbecimentos na agricultura indigena no Baixo Rio Negro. Manaus: EDUA.

Emperaire L.; Velthen, L.H.V.; Oliveira, A.G. de. 2012. Patrimônio cultural imaterial e sistema agrícola no médio Rio Negro, Amazonas. Ciência e Ambiente, 44. Biodiversidade/Sociodiversidade na Amazônia.

Shiva, V. 2003. Monoculturas da mente: perspectivas da biodiversidade e da biotecnologia. São Paulo: Editora Gaia.

Thiago Mota Cardoso thiagotxai@gmail.com 


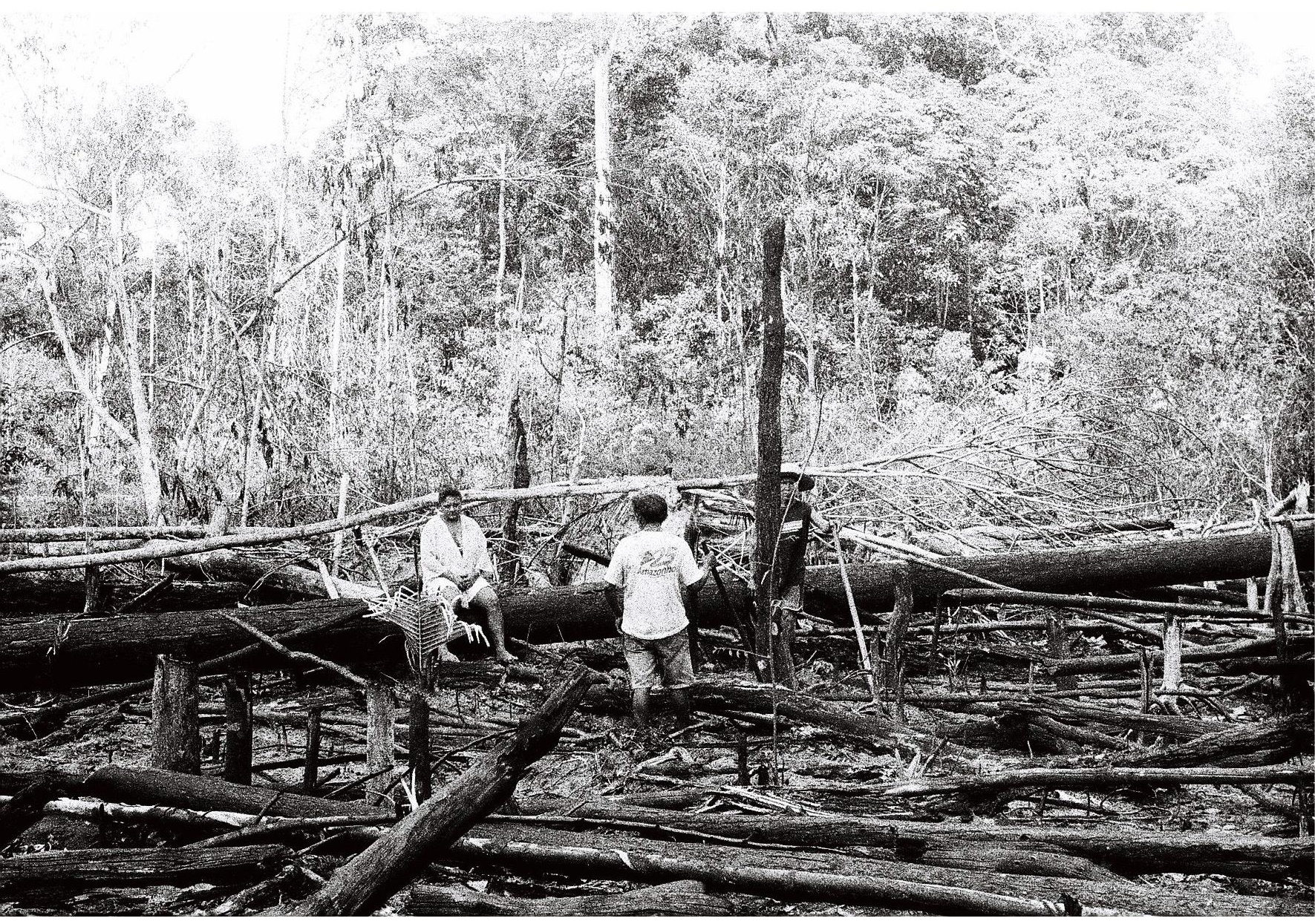

Figura 1 - Abertura da roça, um trabalho eminentemente masculino. Por meios de conhecimentos do clima, do micro-clima, das estações e direção do vento, inicia-se a derrubada de uma pequena parcela da mata ou da capoeira, e o fogo é utilizado. Um grupo de homens da comunidade de Boa Esperança conversam em uma roça já aberta e preparada para o plantio. 


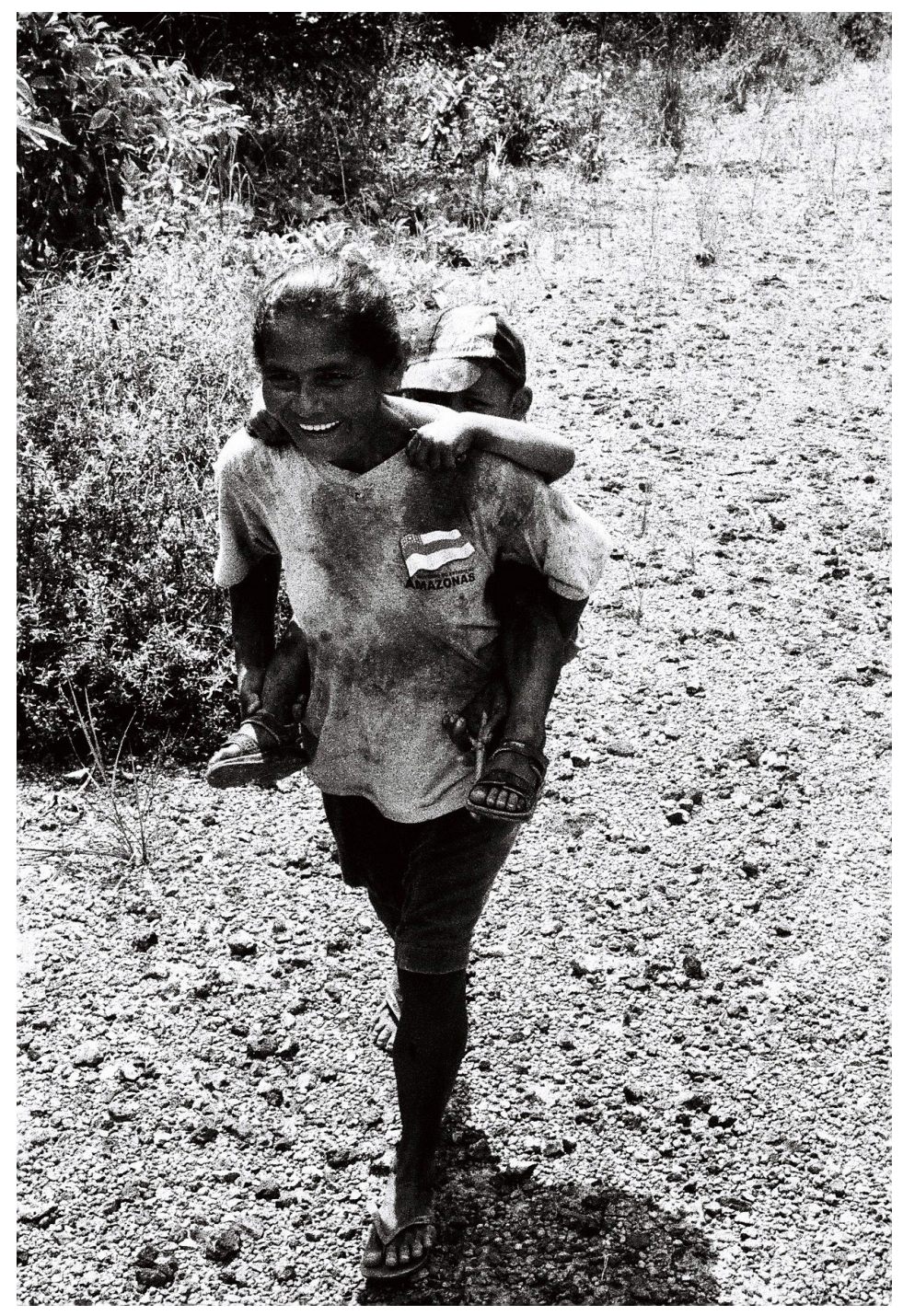

Figura 2 - As mulheres e crianças participam do processo de abertura da roça e da fase de plantio. 


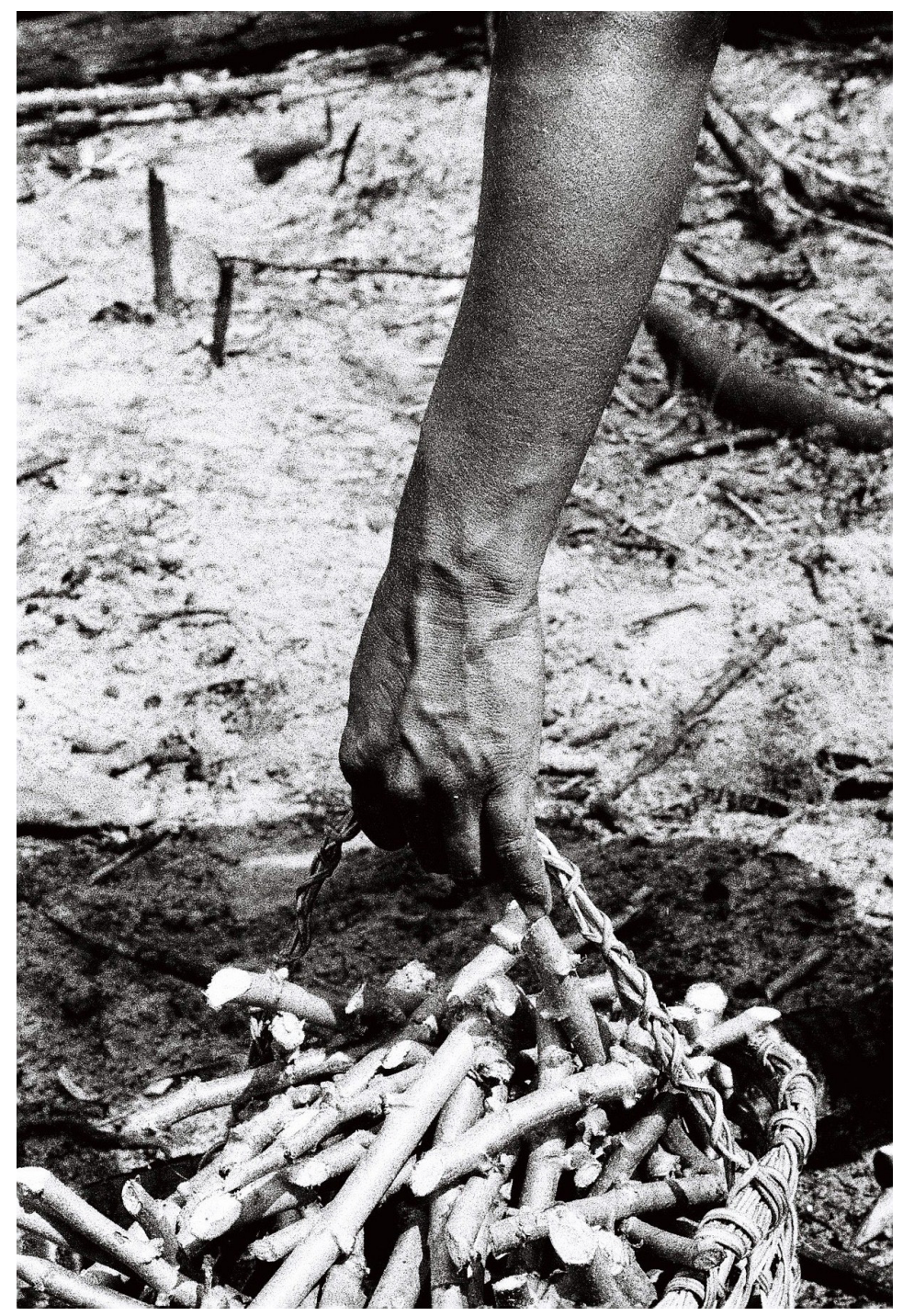

Figura 3 - São elas que escolhem quais plantas serão cultivadas a depender do tipo de terra e sementes disponíveis. Elas carregam a maniva, a "semente da mandioca" que serão deitadas na terra em locais de acordo com o nome da maniva (tracajá, açaí, seis meses, paca). 


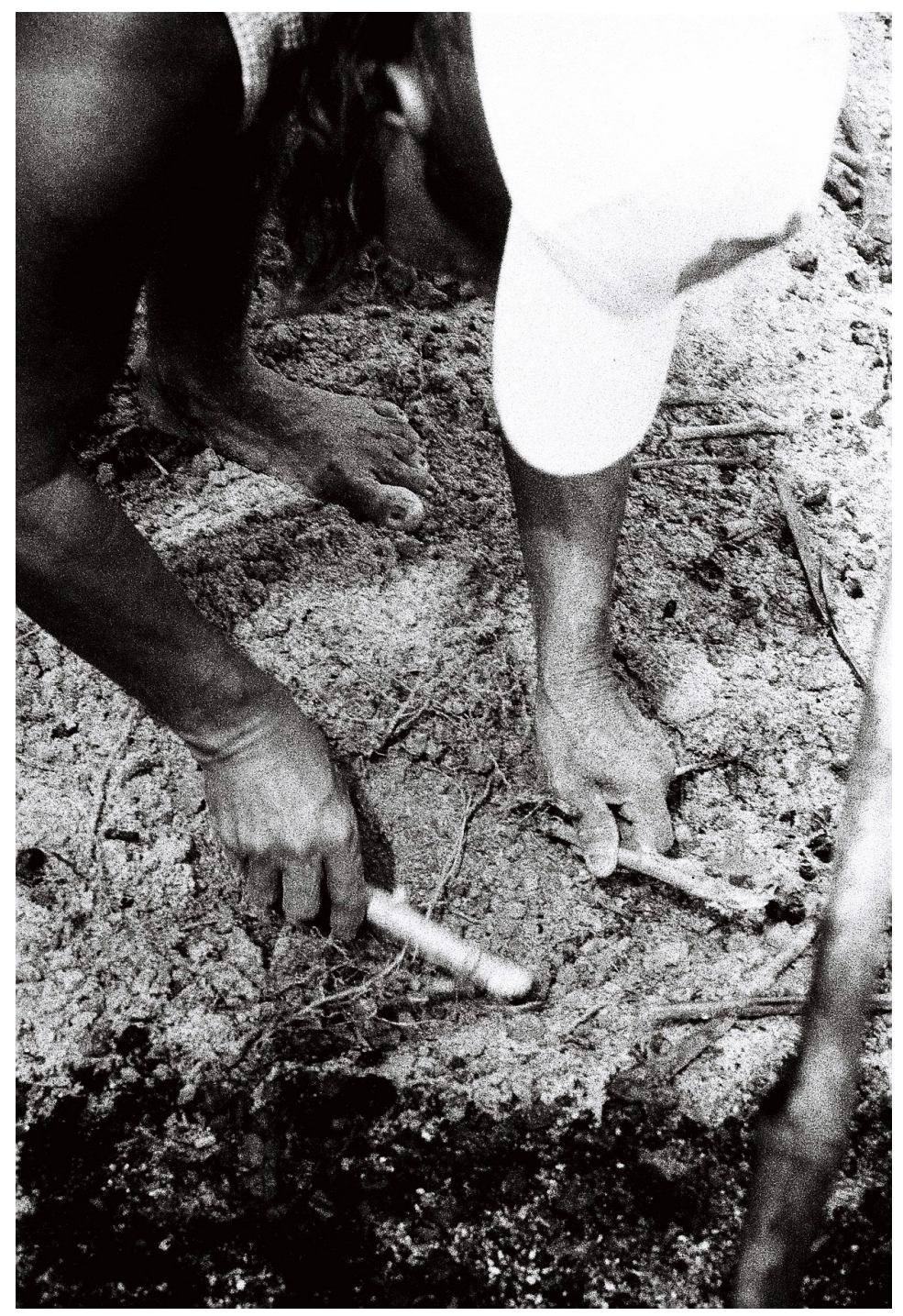

Figura 4 - Plantar é cuidar da maniva, cuida-se como uma filha, assim como o faz a mãe da roça. Adalgisa plantando duas manivas de "olho". 


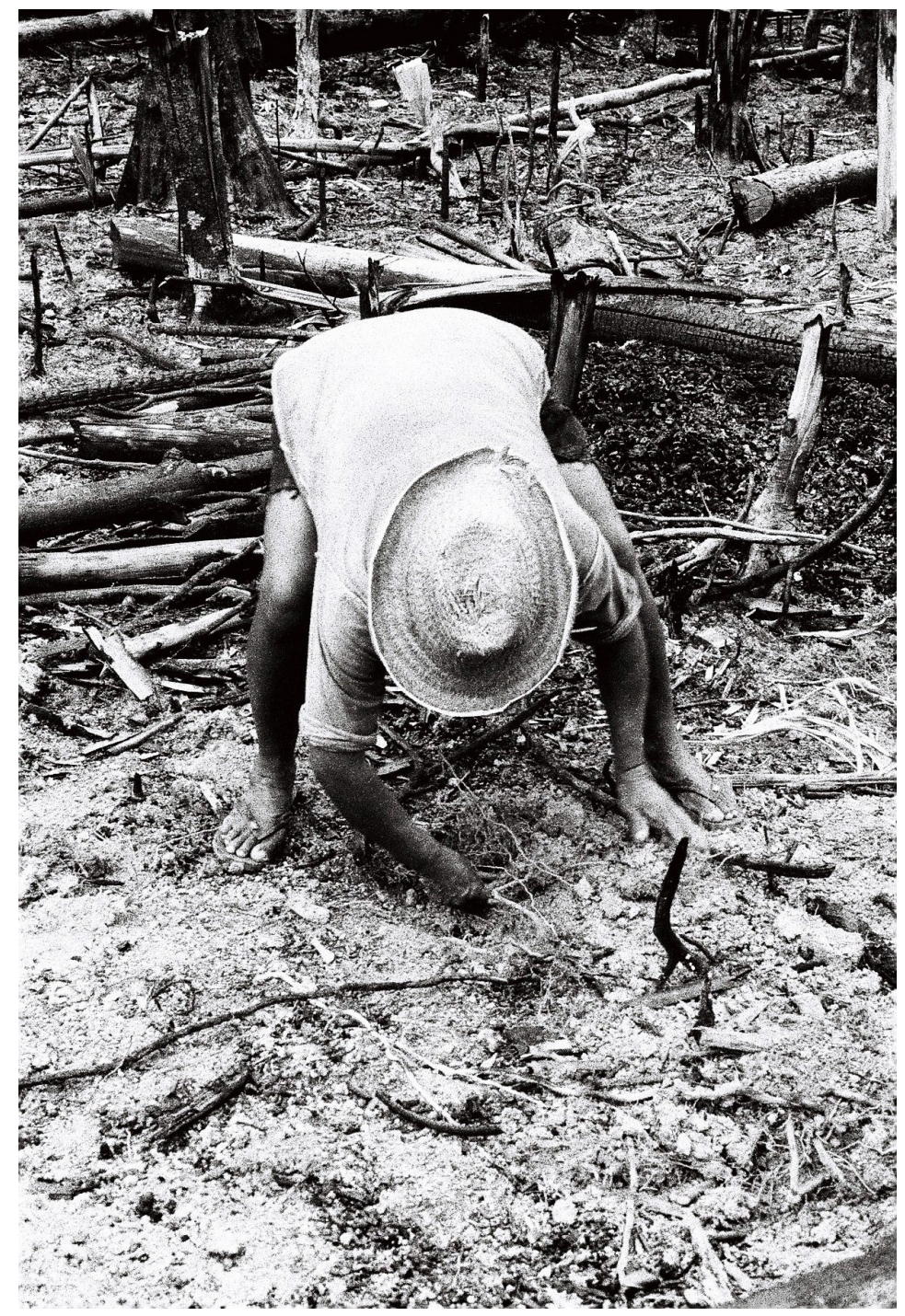

Figura 5 - Dona Arlete, seu corpo se dobra no entrelace com as manivas. 


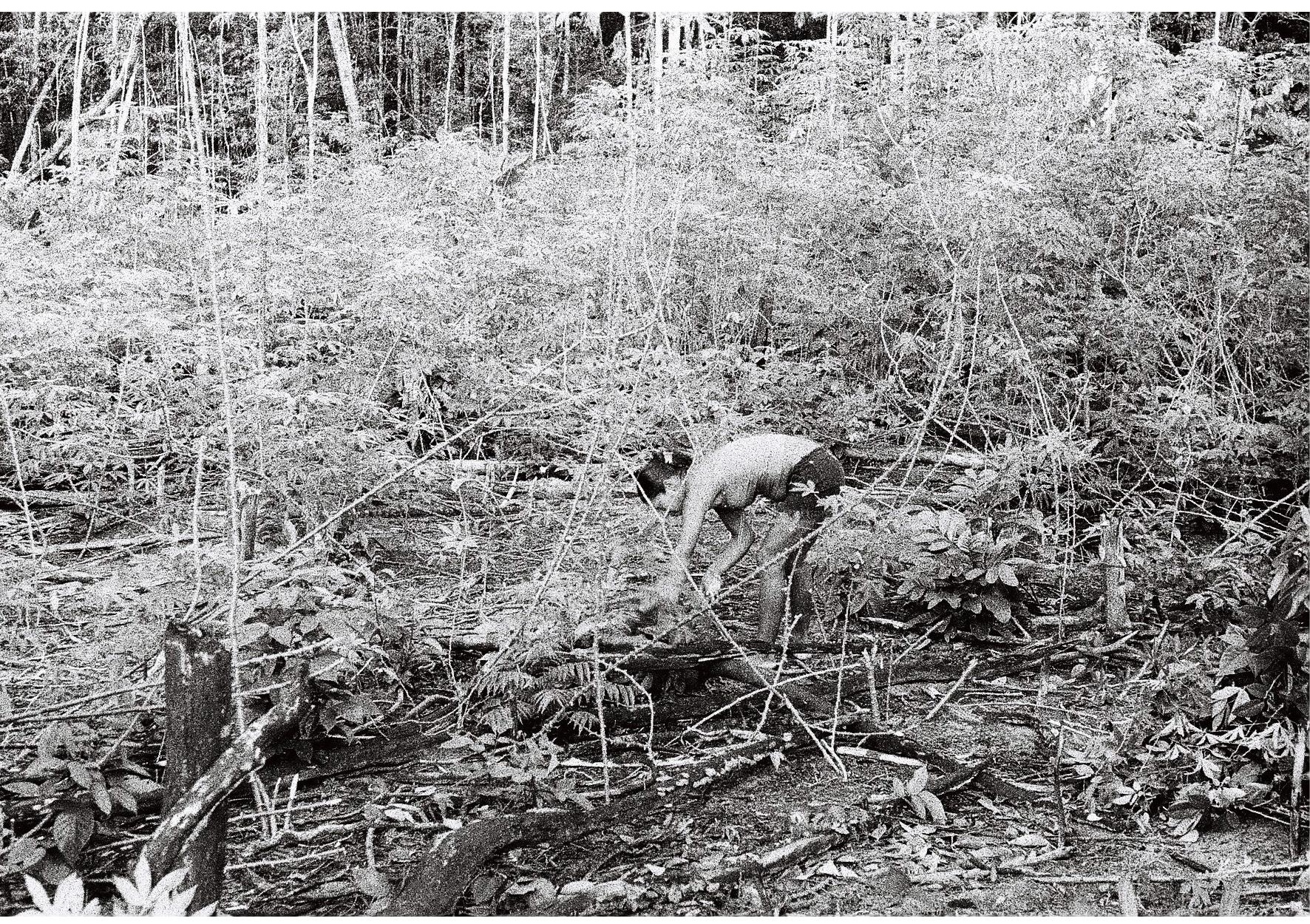

Figura 6 - As manivas vão crescendo junto com outras plantas, animais e insetos, formando um mundo multiespecífico onde a mulher é parte da relação e não a controladora. Juliana, em Nova Esperança, cuidando de sua roça, retirando os "matos" que teimam em ocupar as margens e brechas. 


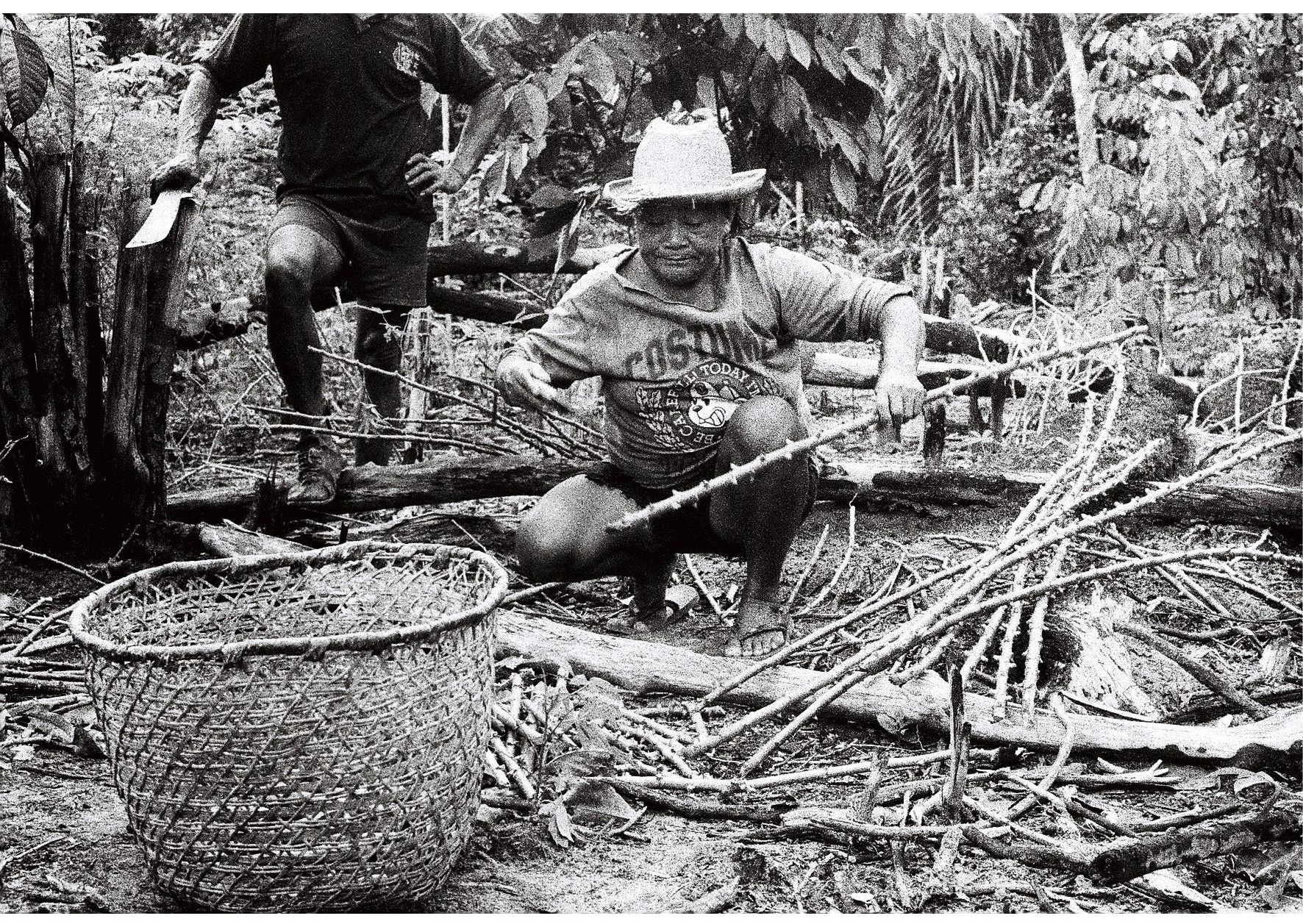

Figura 7 - Após a colheita a maniva é cortada. Parte dela ficará na roça para o "replante" no mesmo espaço ou numa roça nova, outra parte será doada para vizinhos ou parentes, criando uma vasta rede de circulação de manivas, conectando pessoas e coisas na própria comunidade e alhures. Dona Arlete, em Nova esperança, cortando as manivas junto com Praxedes. 


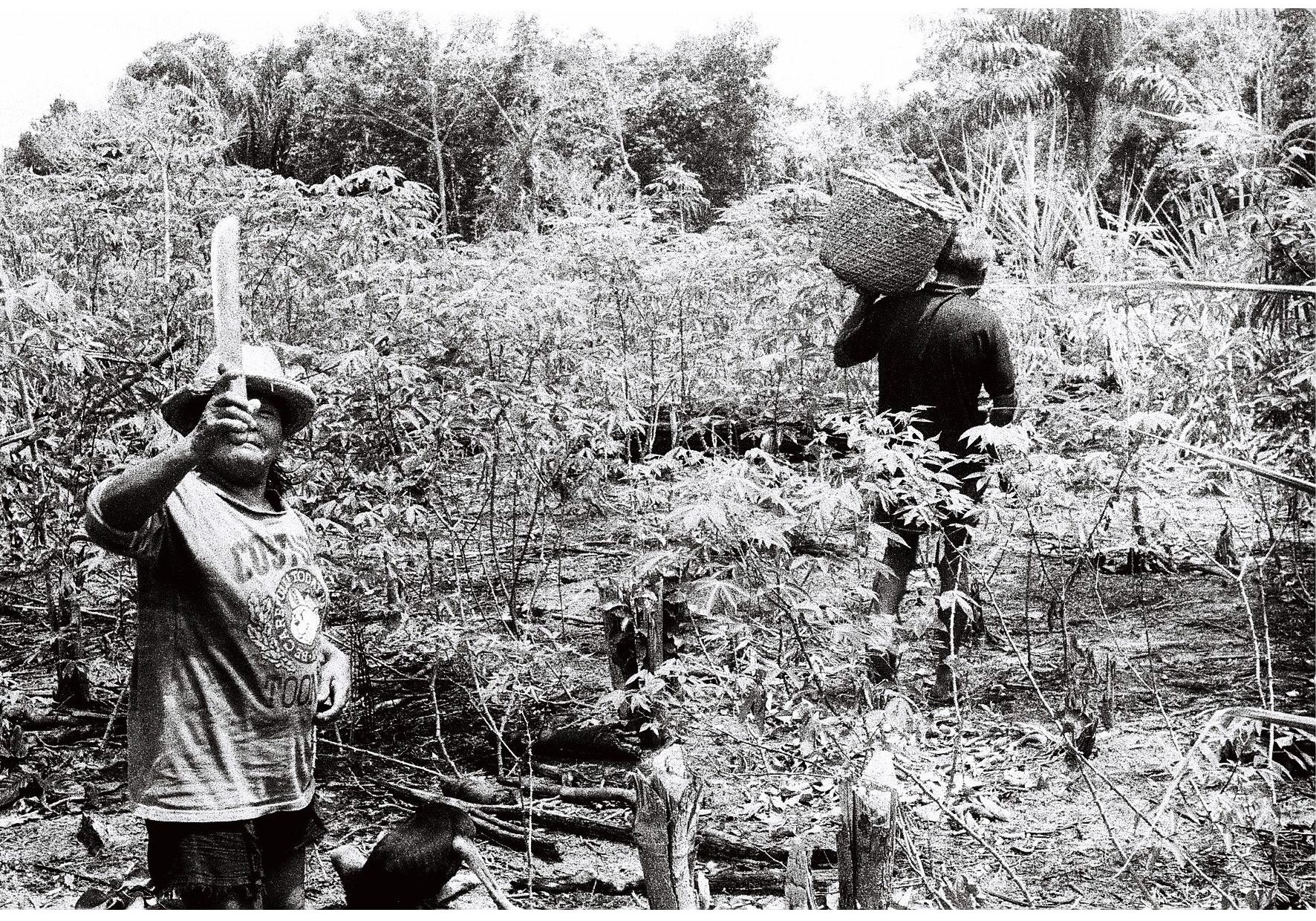

Figura 8 - Ao retirar as mandiocas da terra Dona Arlete e Praxedes as carregam em aturás até a casa de farinha. 


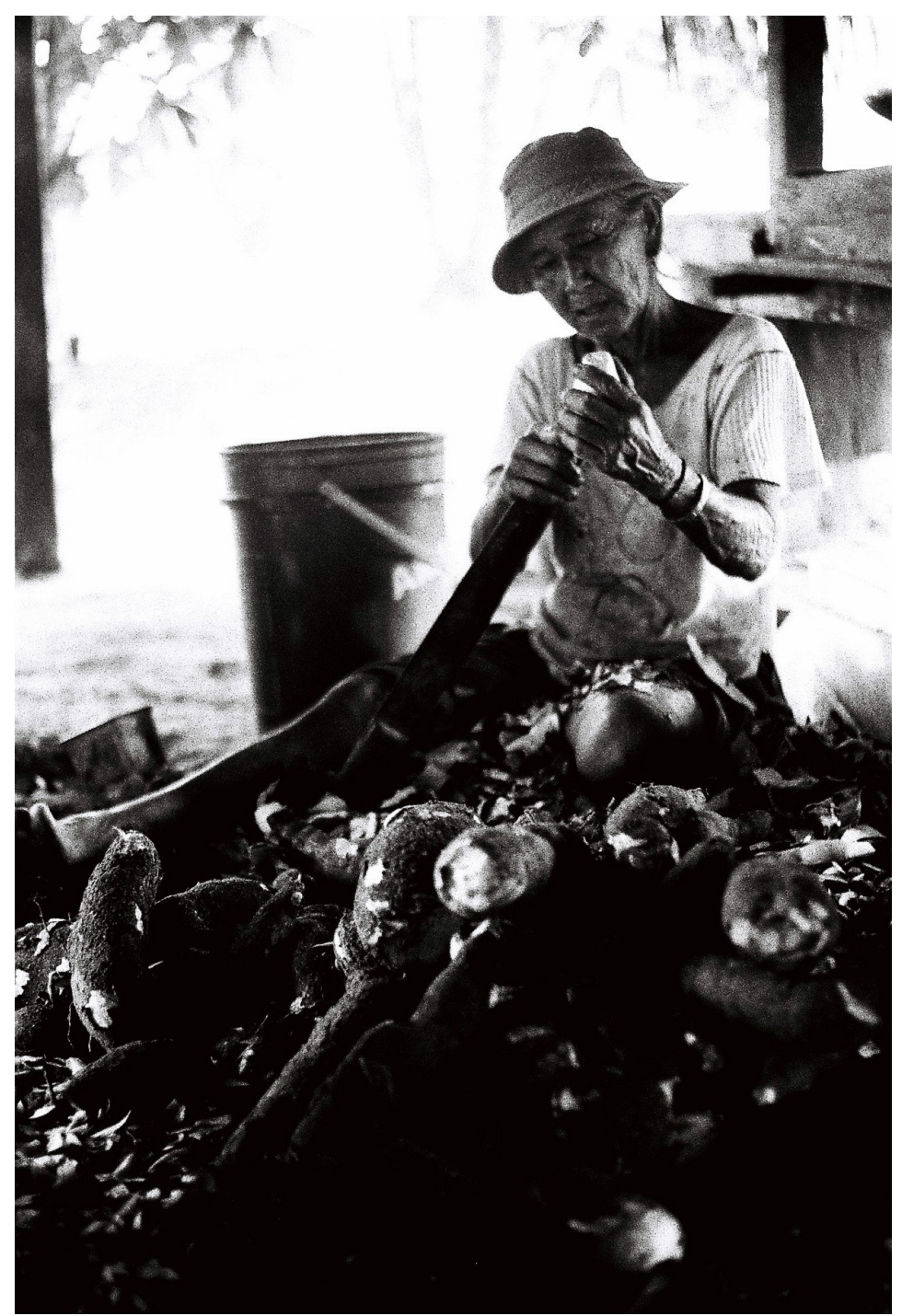

Figura 9 - A mandioca é descascada pela lâmina do terçado de Dona Arlinda em sua casa de farinha, na comunidade Barreirinhas. Participam mulheres, crianças e homens, num momento onde se desfruta conversas, causos e prosas. 


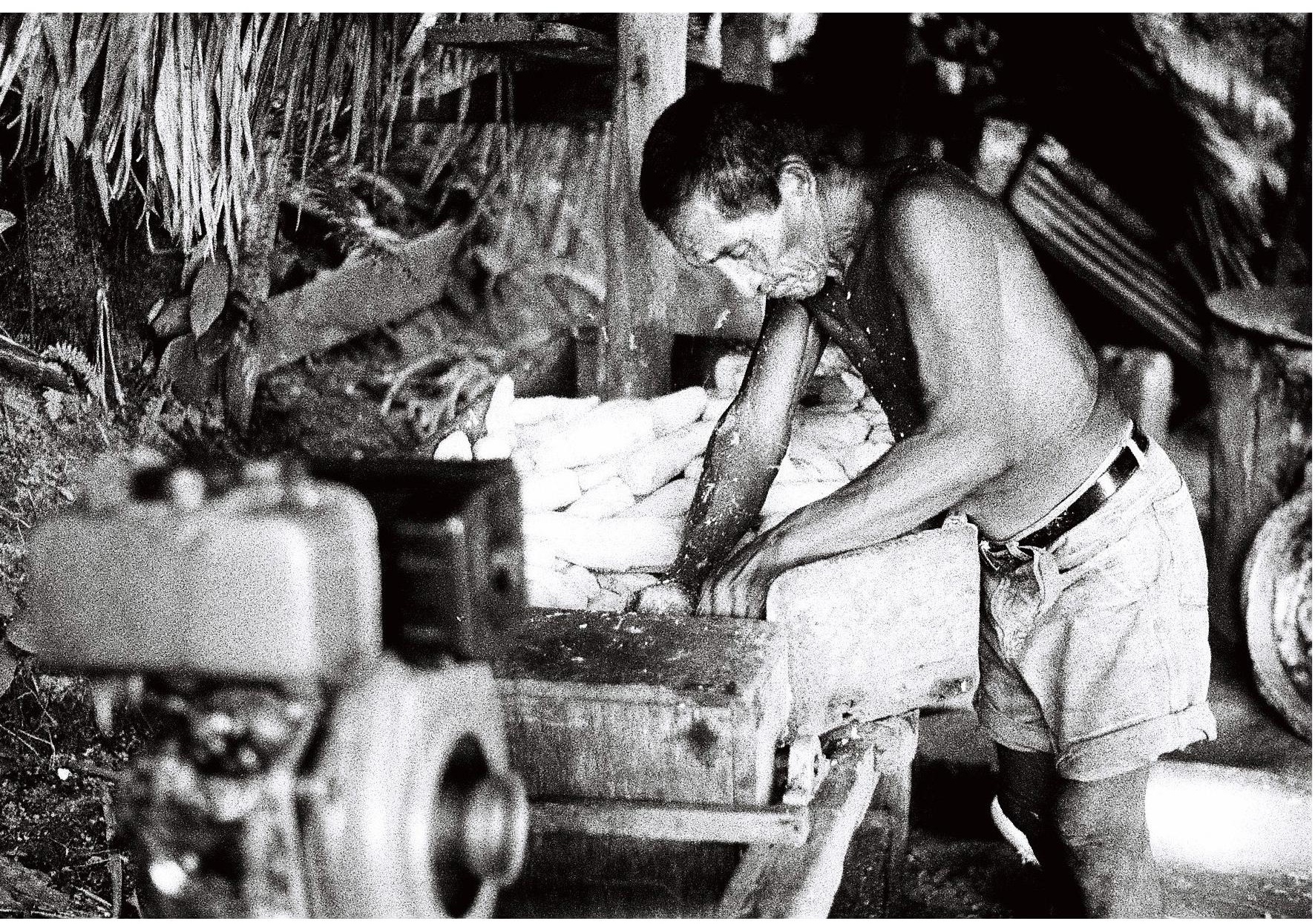

Figura 10 - Neste momento, na casa de farinha, o masculino volta a ter um papel de maior agência. Rafael, na comunidade de Barreirinhas, ralando a raiz para processar a massa da mandioca. 


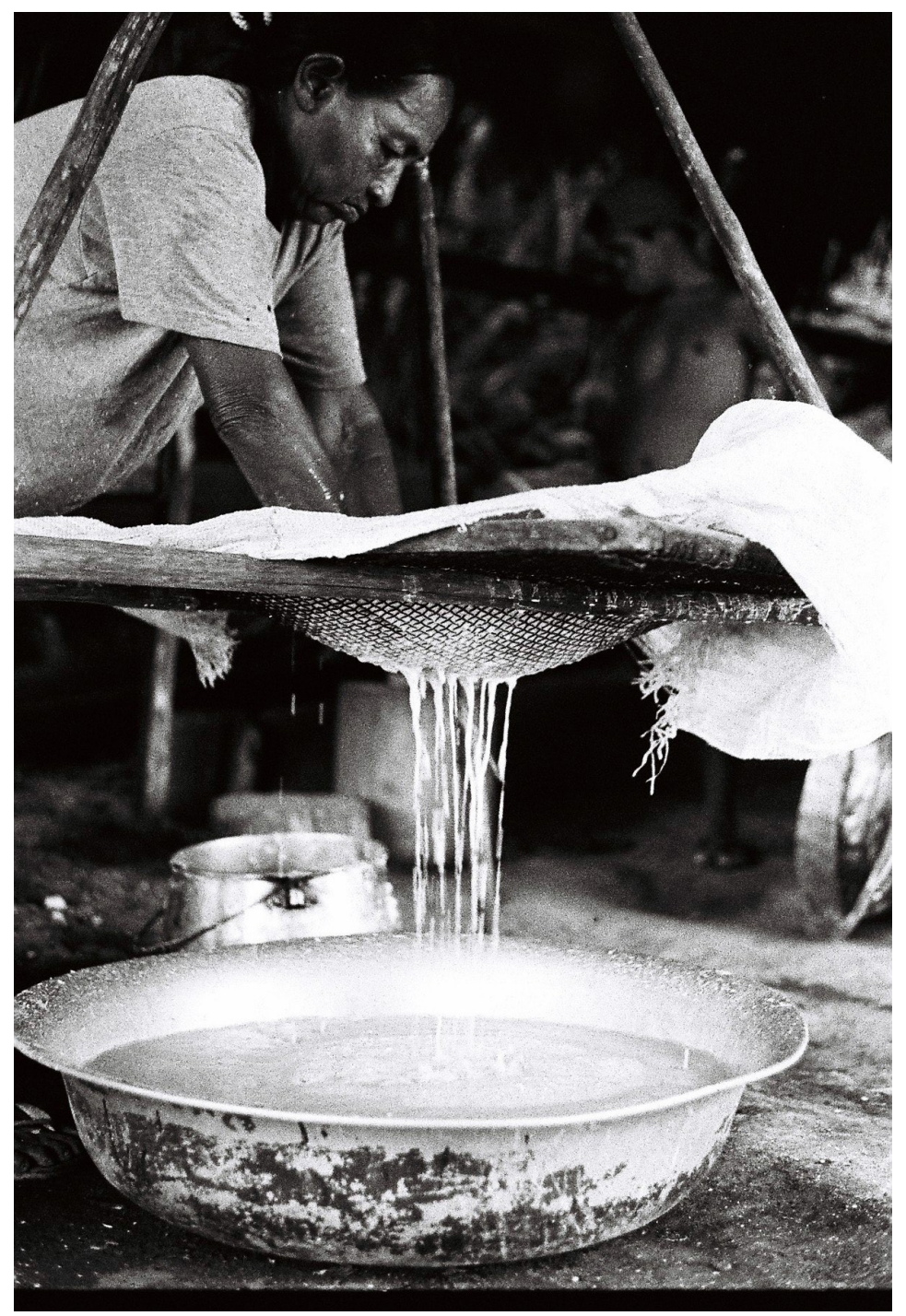

Figura 11 - Cristina, da comunidade Barreirinhas, descansa a massa já ralada e misturada com a puba - raiz de mandioca molhada, onde será peneirada para a retirada da goma e do tucupí. 


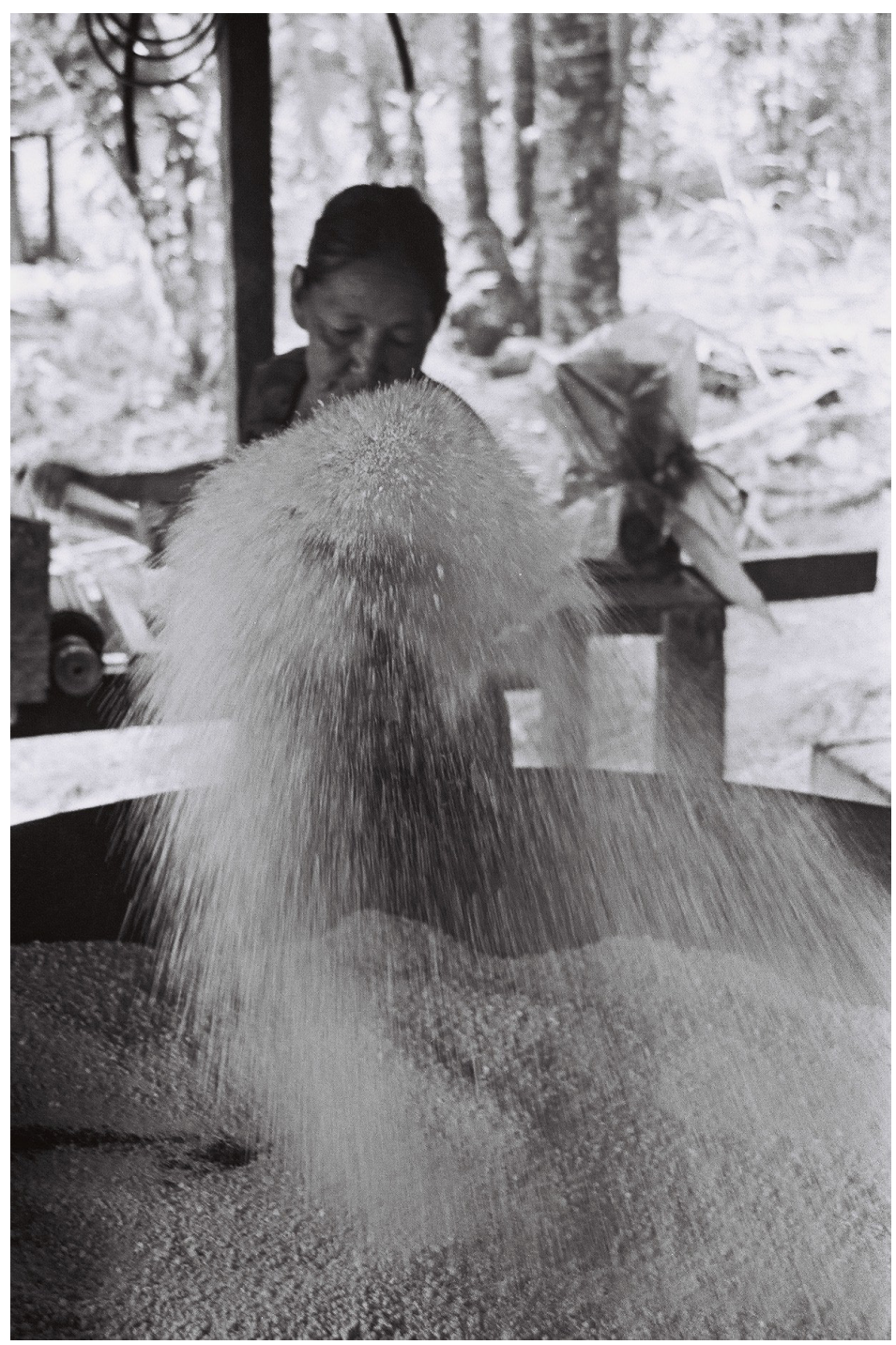

Figura 12 - Por fim, o derradeiro momento de se torrar a farinha. Da mandioca se faz diversas qualidades de farinha, além de mingaus, tapiocas, beijus, bolos e bebidas como o cauim. 